\title{
Deformability of Oxygenated Irreversibly Sickled Cells
}

\author{
Margaret R. Clark, Narla Mohandas, and Stephen B. Shohet, The Cancer \\ Research Institute and Departments of Medicine and Laboratory Medicine, \\ University of California, San Francisco, San Francisco, California 94143
}

\begin{abstract}
A в S T RACT The deformability characteristics of isolated subpopulations of irreversibly sickled cells (ISC) have been studied in an ektacytometer. Analysis of laser diffraction patterns of well-oxygenated cells subjected to shear stress in solutions of varying osmolality has demonstrated a profound influence of mean corpuscular hemoglobin concentration and intracellular viscosity on the deformability of ISC. Virtually undeformable at $290 \operatorname{mos} \mathrm{M}$, ISC became almost totally deformable at $130 \operatorname{mos} M$. In addition, when ISC membranes were loaded with normal hemoglobin at low concentration, they deformed easily in isotonic medium, as did resealed normal cell membranes. The restoration of deformability of ISC upon reduction of their hemoglobin concentration and internal viscosity to normal levels suggests that altered membrane properties are not the primary determinant of decreased deformability in these cells. Rather, cellular dehydration induced by previous sickling would appear to contribute in a major way to their abnormal rheological behavior.
\end{abstract}

\section{INTRODUCTION}

The clinical importance of erythrocyte rheology in sickle cell disease has been generally recognized. In addition to the dramatic loss of cell deformability consequent to deoxygenation and hemoglobin $\mathrm{S}$ polymerization, it has also been noted that oxygenated sickle cells exhibit reduced deformability. Most, if not all, of this decreased deformability has been attributed to irreversibly sickled cells (ISC) ${ }^{1}(1-3)$. Erythrocyte deformability is regulated by three properties of the cell: the relative amount of excess surface area available

Part of this material has been presented previously in abstract form: 1978. Blood. 52(Suppl. 1): 96.

This is publication No. 2 of the MacMillan-Cargill Hematology Research Laboratory at the University of California, San Francisco, Calif.

Received for publication 4 June 1979 and in revised form 13 August 1979.

${ }^{1}$ Abbreviations used in this paper: ISC, irreversibly sickled cell(s); MCHC, mean corpuscular hemoglobin concentration(s); PBS, phosphate-buffered saline. for cellular deformation, the internal viscosity of the cell, and the intrinsic flexibility of the membrane itself. Evidence for abnormalities in each of these factors has been reported for ISC. One proposed mechanism for the generation of ISC involves loss of membrane from the tips of spicules of sickled cells as they unsickle (4). Because of the high surface-area:volume ratio of the small spherical vesicles that would be lost in such a process, the residual cell might be expected to have a reduced surface-area:volume ratio. On the other hand, decrease in cell water, with attendant increase in mean corpuscular hemoglobin concentration (MCHC) and intracellular viscosity, is well-documented in ISC (5-7). Glader and Nathan (5) have shown that a specific potassium leak that entails cellular dehydration is critical in the production of ISC. Finally, several authors have concluded that ISC membranes have a reduction in the membrane viscoelastic modulus, and that a relatively rigid membrane limits whole cell deformability (1, 2, 8-10). Membrane-associated $\mathrm{Ca}$ is elevated in ISC $(11,12)$. Because excess $\mathrm{Ca}$ appears to induce membrane "stiffening" in normal cells, Ca interaction with the membrane is widely accepted as a mechanism for the reduced deformability of ISC.

Recently, we had the opportunity to study another type of dehydrated erythrocyte from patients with a disorder termed "desiccytosis" (13). In these studies we found that the osmolality of the suspending medium exerted a profound effect on cell deformability, which suggested that the increased MCHC of the cells was a major cause of their severely reduced deformability in isotonic medium (14). Similarly, we have now found that the high MCHC of ISC dominated the behavior of these cells under shear stress, even when the cells were fully oxygenated. Thus it appears that increased internal viscosity may be at least as important as impaired membrane flexibility in the rheological behavior of ISC.

\section{METHODS}

In eight separate experiments, which employed blood from eight different patients with homozygous sickle cell disease, ISC were separated on Stractan II (St. Regis Paper Co., 
Tacoma, Wash.) density gradients as previously described (6). In these experiments, however, linear, continuous gradients, ranging in density from 1.074 to $1.124 \mathrm{~g} / \mathrm{ml}$ were used instead of discontinuous gradients (Beckman gradient former, Beckman Instruments, Inc., Spinco Div., Palo Alto, Calif.). These gradients were formed upon a Stractan cushion whose density was $1.144 \mathrm{~g} / \mathrm{dl}$. The cells that accumulated at the bottom of the gradient on top of the cushion consisted of 75-85\% ISC, mixed with a small proportion of dense spherocytes and rare discoid cells. The MCHC of the ISC subpopulations varied from 44 to $51 \mathrm{~g} / \mathrm{dl}$, as determined from centrifugal measurement of hematocrits and spectrophotometric measurement of hemoglobin using cyanomethemoglobin reagent. A reference population of mature discoid cells, with MCHC of 33-35 g/dl, was taken from the middle of the gradients. In three experiments, the ISC subpopulation was further separated on a second Stractan gradient, whose osmotic concentration was $125 \mathrm{mosmol} / \mathrm{kg}$. The density range was the same as for the 290-mosM gradient. Before recentrifugation in the hypotonic gradient, the ISC were washed twice in 125 mosM phosphate-buffered saline $(10 \mathrm{mM}$ sodium phosphate, $\mathrm{pH}$ 7.4). After separation, cells were removed from the gradients using a Pasteur pipette and were then washed free of Stractan in phosphate-buffered saline that contained $10 \mathrm{mM}$ glucose and $5 \mathrm{mM} \mathrm{KCl} \mathrm{(10} \mathrm{mM} \mathrm{phosphate,} \mathrm{pH} 7.4)$.

Deformability was evaluated using an ektacytometer, designed and previously described by Bessis and Mohandas (15). For the deformability studies, the cells were suspended in phosphate-buffered saline (PBS) that contained $25 \mathrm{~g}$ of dextran (40,000 mol wt, Sigma Chemical Co., St. Louis, Mo.) per $100 \mathrm{ml}$ PBS. For measurements in hypotonic medium, PBS was prepared at various osmolalities with a constant phosphate buffer concentration of $10 \mathrm{mM}$. Osmolalities were determined with a Wescor vapor pressure osmometer (Wescor Inc., Logan, Utah), and the dextran was then added.

The osmotic contribution of the dextran itself was determined both by direct measurement in the $25 \%$ solutions, and by extrapolation of measurements of the osmolality of $25 \%$ dextran in 100 mosM PBS diluted in varying proportions with 100 mosM PBS without dextran. These measurements indicated that in solutions containing $25 \mathrm{~g}$ of dextran per $100 \mathrm{ml}$ of PBS, the dextran contributed $55 \pm 5 \mathrm{mosmol} / \mathrm{kg}$ to the total osmotic strength. In previous reports $(14,16)$, the contribution of dextran to the osmolality was ignored. Thus the actual osmolalities of the solutions in which deformability was measured were higher than the reported values by as much as 55 mosM. Nevertheless, the overall conclusions of these studies are not affected. In making up cell suspensions for use in the ektacytometer, $\sim 20 \mu$ l of washed cells (50\% hematocrit) was added to $6 \mathrm{ml}$ of dextran medium immediately before measurements were made. ${ }^{2}$ Laser diffraction patterns obtained at specified values of shear stress in the ektacytometer were photographed, and dimensions of the diffraction patterns were measured using the photographic negatives. Also, direct measurements of the diffraction patterns were taken during experiments from graph paper mounted to intercept the diffracted light from the instrument.

For evaluation of cell morphology, cells were washed in PBS at various osmolalities and were fixed by the addition of glutaraldehyde to a concentration of $0.2 \%$. The samples were then processed by the usual methods for scanning electron microscopy (17).

Artificially dehydrated cells were prepared using nystatin to induce a reversible increase in membrane permeability to

${ }^{2}$ Allowing the cells to stand in dextran for periods of up to 30 min did not alter the cell deformability. cations. With the method previously described, we employed nystatin and sucrose simultaneously to adjust both the monovalent cation concentrations and the water content of normal control cells to the desired levels (14). To produce membrane "stiffening" in normal cells, without alteration of MCHC or surface-area:volume ratio, cells washed in isotonic PBS were heated to $48^{\circ} \mathrm{C}$ for $10 \mathrm{~min}(18)$.

In an effort to measure the deformability of ISC membranes without a contribution from sickle hemoglobin, we prepared erythrocyte hybrids, or hemoglobin-exchanged cells. The technique used for hemoglobin exchange was identical to that previously reported (19). In our experiments, three types of membrane donor cells were used, ISC, normal cells, and normal cells heated to $48^{\circ} \mathrm{C}$ for $10 \mathrm{~min}$. All three types of hybrids prepared from these cells contained hemoglobin obtained from outdated blood-bank cells.

\section{RESULTS}

Fig. 1 shows representative ektacytometer diffraction patterns obtained from sickle cell subpopulations of various densities and MCHC obtained from the Stractan gradient in a typical one of the eight experiments. Unseparated cells presented a double pattern, composed of a horizontal ellipse superimposed upon the usual vertical ellipse characteristic of normally deforming cells (not shown). This composite pattern was the result of heterogeneity in the cells, as is shown by the patterns obtained from the separated sickle cell

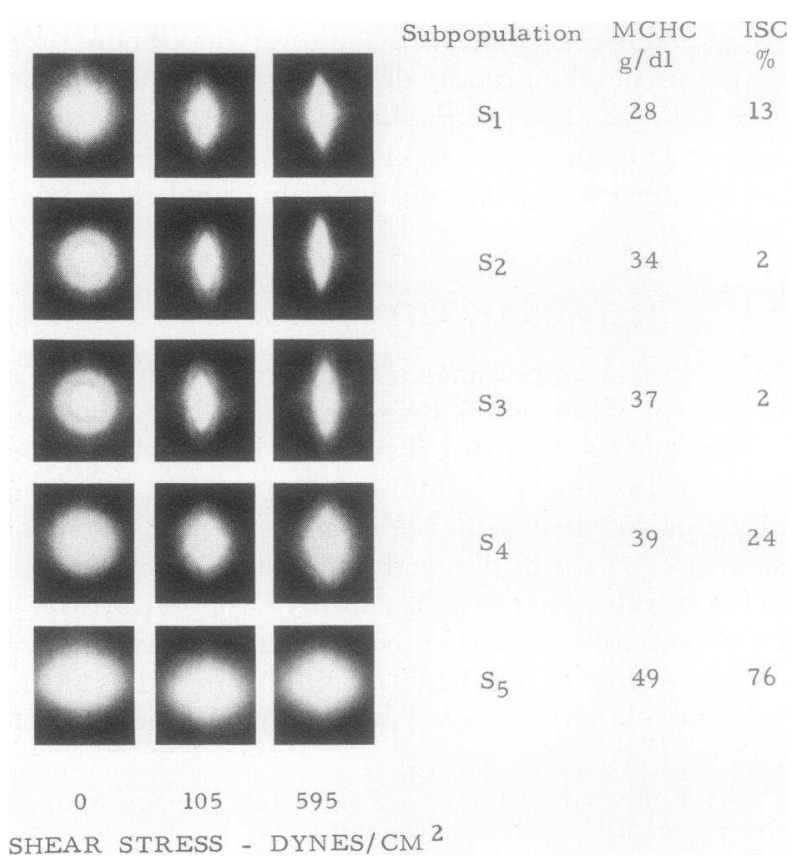

FIGURE 1 Laser diffraction patterns of isolated subpopulations of sickle cells. The patterns were photographed while cells were subjected to shear stress at the indicated intensities in the ektacytometer. $S_{1}$ was the top, low-density subpopulation, and $S_{5}$ was the bottom subpopulation, containing $76 \%$ ISC. Note the characteristic horizontal diffraction pattern from the ISC-rich sample. 


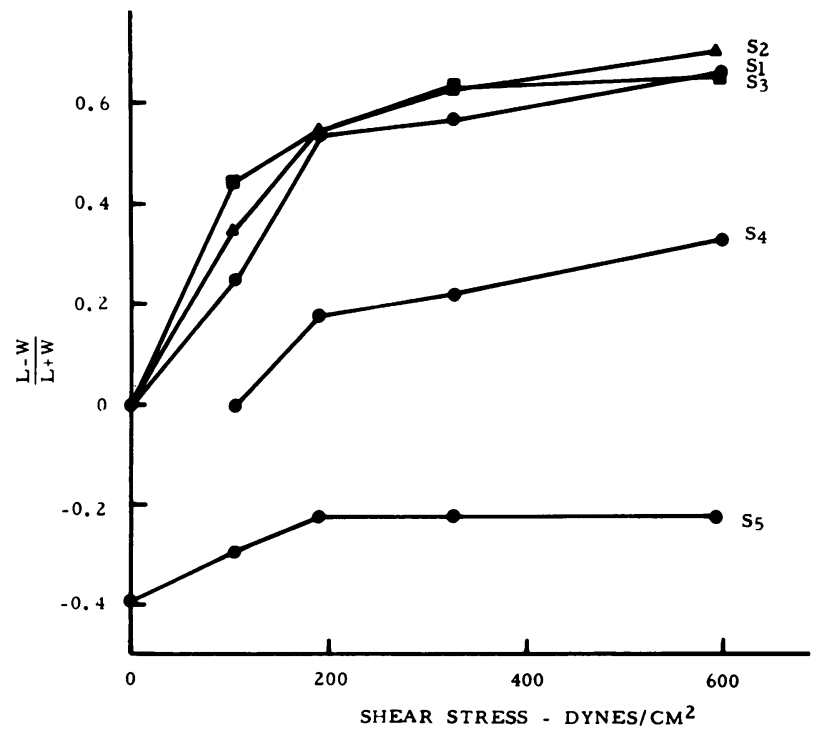

FIGURE 2 Deformation of isolated subpopulations of sickle cells. Deformation is represented by the measured value of the length minus the width of the diffraction pattern $(L-W)$ divided by the sum $(L+W)$. Values for this quantity obtained from the various Stractan-separated sickle cells are plotted as a function of increasing applied shear stress.

subpopulations. Cells with MCHC below $37 \mathrm{~g} / \mathrm{dl}$, collected from the upper portions of the gradient, deformed normally in isotonic medium. Cells collected from the lower region of the gradient contained increasing proportions of ISC, with higher MCHC, and they produced the characteristic horizontal diffraction pattern of ISC, described by Bessis and Mohandas (20). The patterns of the deforming cells from the top of the gradient, like those of normal cells, changed from circles to progressively elongated ellipses with application of increasing shear stress. In contrast, the horizontal ellipses of stationary ISC changed very little up to the maximum shear stress used. A graphical representation of this observation is given in Fig. 2. Here we have plotted the value of the mathematical quantity, $(\mathrm{L}-\mathrm{W}) /(\mathrm{L}+\mathrm{W})$, where $\mathrm{L}$ is the measured vertical dimension of the diffraction pattern and $\mathrm{W}$ is the horizontal dimension. This quantity represents the "pattern ellipticity," and it is a measure of cell deformation. ${ }^{3}$ When ISC-rich subpopulations from the bottom of Stractan gradients (MCHC: 44-46 g/dl) were washed

\footnotetext{
${ }^{3}$ For the nondeforming ISC populations, the pattern ellipticity has a negative sign, which is a consequence of the perpendicular orientation of the cells and the diffraction pattern. For the double patterns, produced by mixed populations of deforming cells and ISC, this quantity is not strictly defined. However, it can be used in a qualitative way to note that the behavior of mixed populations, such as $\mathrm{S}_{4}$ in Fig. 2, is intermediate between the behavior of discoid cells $\left(S_{1}\right.$, $S_{2}$, and $\left.S_{3}\right)$ and ISC $\left(S_{5}\right)$.
}

in hypotonic PBS and resuspended in hypotonic dextran solutions, the cells became deformable. This is demonstrated by the diffraction patterns in Fig. 3. With decreasing osmolality down to $130 \operatorname{mos} M$, the ISC showed linear osmotic behavior and took up increasing amounts of water, reducing their MCHC (Fig. 4). When the osmolality was reduced to $180 \operatorname{mos} \mathrm{M}$, the ektacytometer patterns revealed the presence of a double population of cells, some deformable, others undeformable (Fig. 3). As the osmolality was further lowered to $130 \operatorname{mosM}$ (MCHC: $32-35 \mathrm{~g} / \mathrm{dl}$ ), virtually all the ISC became deformable, as was shown by the absence of the horizontal ellipse in the diffraction pattern. These changes were also revealed in values of $(\mathrm{L}-\mathrm{W}) /$ $(\mathrm{L}+\mathrm{W})$. The negative values for this "ellipticity function" obtained for ISC in isotonic medium showed a smooth transition to positive values as the osmolality was reduced. The maximum elongation of the pattern at high shear stress approached that of normal cells and discoid sickle cells (Fig. 2). The MCHC of the ISC in the experiment from which these particular data were obtained was $44 \mathrm{~g} / \mathrm{dl}$ at $290 \operatorname{mosM}$ and was reduced to $32 \mathrm{~g} / \mathrm{dl}$ at $125 \mathrm{mosM}$. The MCHC at $180 \operatorname{mosM}$, at which a double population was first observable in the ektacytometer pattern, was $38 \mathrm{~g} / \mathrm{dl}$. Examination of the supernate of hypotonic cell suspensions after centrifugation verified that there was no hemolysis of the ISC population down to 75 mosM.

The observation of a double population of deforming and nondeforming cells in 180 -mosM solutions and uniformly deforming cells in 130 -mosM solutions suggested that the ISC populations taken from the bottom of the Stractan gradients were still heterogeneous with respect to their capacity to take up water in hypotonic solutions. To assess this possibility, we performed
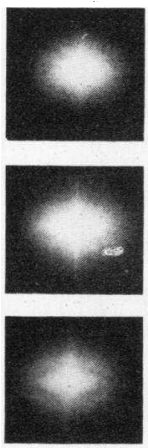

0
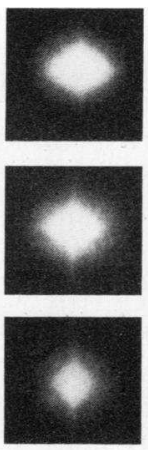

105
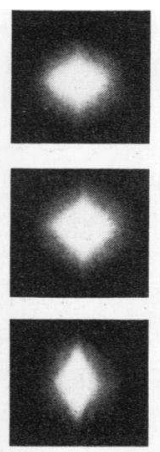

595
SHEAR STRESS - DYNES/CM ${ }^{2}$

Figure 3 Laser diffraction patterns of ISC at various osmolalities. Isolated ISC were suspended in dextran solution at the specified osmolalities and subjected to shear stress at the indicated values. Note the vertical pattern characteristic of deforming cells at low osmolality and high shear stress. 

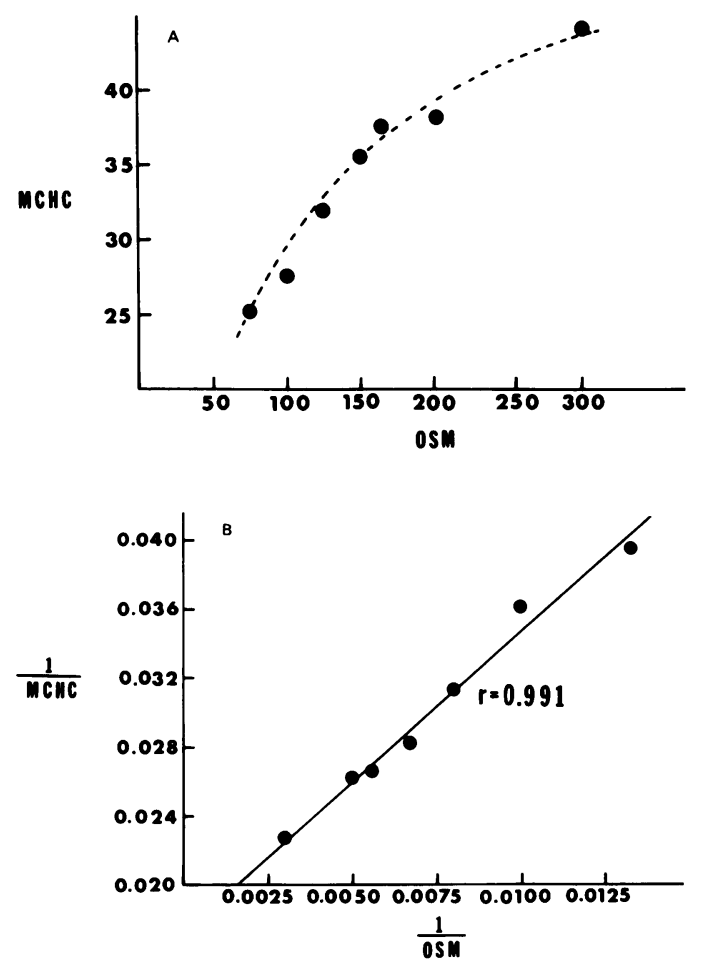

Figure 4 MCHC of ISC as a function of osmolality. Data are plotted directly, as (A) MCHC vs. osmolality and (B) as a double reciprocal plot, which gives a straight line. An equation describing this linear behavior can be written: 1/ $\mathrm{MCHC}=1 / \mathrm{MCH} \mathrm{V}_{\text {cell solids }}+\left(\mathrm{V}_{\mathrm{H}_{2} \mathrm{O}}^{290} \times 290 /\right.$ osmolality, where $\mathrm{V}_{\text {cell solids }}$ is the volume occupied by cell solids, and $\mathrm{V}_{\mathrm{H}_{2} \mathrm{O}}^{290}$ is the volume of cell water at 290 mosM.

three experiments employing a secondary Stractan centrifugation on linear gradients prepared at 125 mosM, with the same density range as the isotonic gradients. ISC taken from the bottom of the 290-mosM gradient were washed in 125 mosM PBS and then recentrifuged on the hypotonic gradient. A further separation of the ISC-rich cell population into three subpopulations was thereby obtained. In these experiments the condensed band of ISC at the bottom of the 290-mos M gradient was spread out over a broad range of lower densities on the 125 -mosM gradient. The MCHC at $125 \operatorname{mosM}$ for the three populations in a representative experiment were 30,35 , and $38 \mathrm{~g} / \mathrm{dl}$. They comprised 47,38 , and $15 \%$ of the total ISC, respectively. The deformability of each subpopulation was measured at 180 and $130 \operatorname{mos} \mathrm{M}$. At $180 \operatorname{mos} \mathrm{M}$ the least dense fraction deformed partially, and the most dense one did not deform at all. At $130 \operatorname{mos} M$ the least dense fraction deformed completely, and the most dense one deformed partially, showing a double diffraction pattern. The intermediate-density subpopulation showed deformability behavior intermediate between these two extremes.
Because ISC contained reduced quantities of monovalent cations, they were not maximally swollen even at 125 mos M. This is evident from Fig. 5, which shows scanning electron micrographs of a total ISC population fixed at 290 mosM and of each of the three ISC subpopulations fixed at $125 \operatorname{mos}$ M. It can be seen that some swelling occurred in the hypotonic medium, but that the dehydrated ISC, which appeared flattened at $290 \operatorname{mos} \mathrm{M}$, did not take up enough water in 125mosM solution to lose their concavities completely.

As a control for our measurements of deformability of ISC at different osmolalities, we prepared artificially dehydrated normal cells, with nystatin and sucrose to adjust the cation and water content to desired levels (14). These artificially dehydrated cells showed the same dependence of their deformability upon MCHC as the naturally dehydrated ISC. This is shown by the data from one experiment summarized in Fig. 6, which contains plots of deformability data for normal cells treated with nystatin to produce an $\mathrm{MCHC}$ of $44 \mathrm{~g} / \mathrm{dl}$ in isotonic medium. At $290 \mathrm{mos} M$ the cells were completely undeformable, and at $180 \operatorname{mos} \mathrm{M}$, a double population was observed. However, as the medium osmolality was reduced to $155 \mathrm{mosM}$, with concomitant reduction of MCHC to $\sim 34 \mathrm{~g} / \mathrm{dl}$, normal deformability was restored.

In an effort to assess membrane flexibility of ISC, independent of the effects of concentrated hemoglobin $\mathrm{S}$, we prepared hemoglobin-exchanged "erythrocyte hybrids" by resealing ISC membranes around normal hemoglobin A. Control hybrids for the study were prepared with membranes from normal cells and from normal cells that had been heated to $48^{\circ} \mathrm{C}$ for $10 \mathrm{~min}$. This gentle heating has been shown by Rakow and
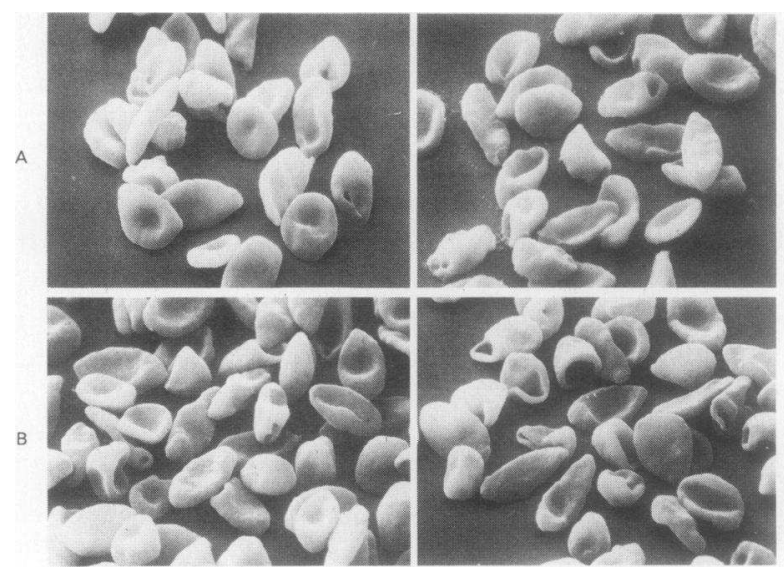

FIGURE 5 Scanning electron micrographs of ISC and hypotonic ISC subpopulations. (A) Total ISC population collected from an isotonic Stractan gradient, fixed at $290 \mathrm{mosmol}$. (B), (C), and (D) Top, middle, and bottom subpopulations, respectively, of ISC collected from secondary 125-mosM Stractan gradient. Cells were fixed at 125 mosM. 


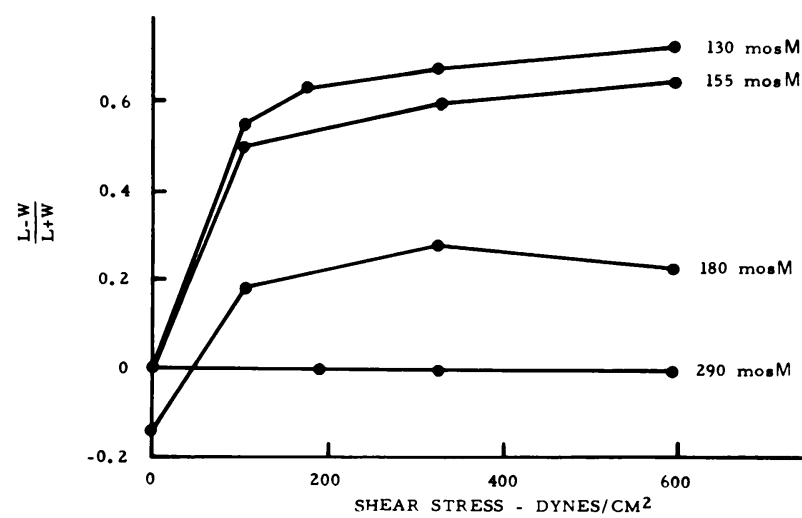

FIGURE 6 Deformation of artificially dehydrated cells at various osmolalities. $(\mathrm{L}-\mathrm{W}) /(\mathrm{L}+\mathrm{W})$ from diffraction patterns were plotted as a function of applied shear stress. Cells were dehydrated to an MCHC of $\mathbf{4 4} \mathrm{g} / \mathrm{dl}$ using nystatin and were subjected to shear stress at the indicated osmolalities.

Hochmuth (18) to produce a specific stiffening of the membrane without alteration of erythrocyte shape or MCHC. It does, however, cause a reduction in deformability, which can be detected in the ektacytometer. This is illustrated by the data in Fig. 7, which contains a graph of $(L-W) /(L+W)$ vs. shear stress for heated cells, normal control cells, and ISC. It is evident that deformation of the heated cells at all shear stress values was significantly reduced from that of untreated cells. It is also clear that the heated cells did undergo substantial deformation, unlike the ISC.

Deformation behavior of the hybrids was not identical to that of the intact cells. Normal cell hybrids de-

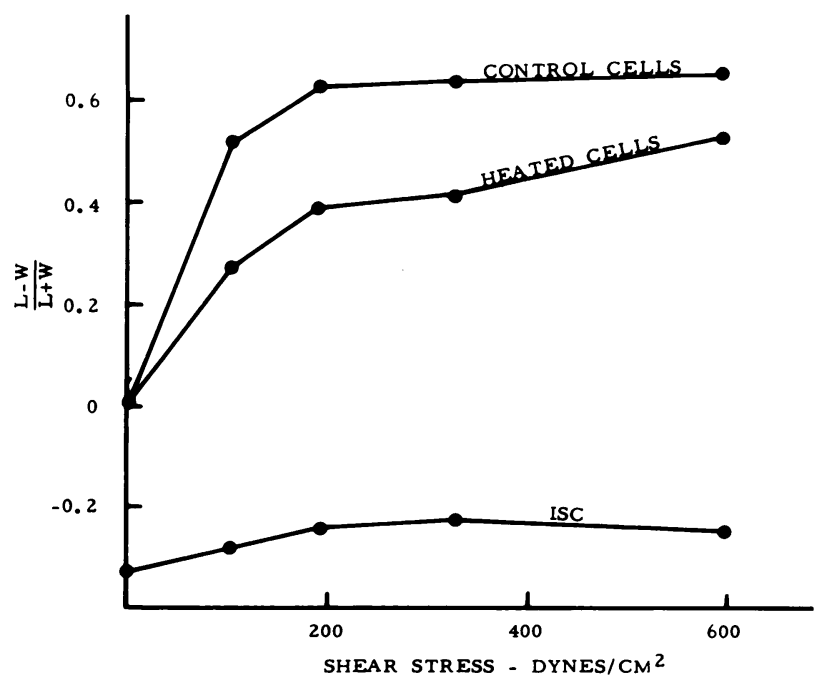

Figure 7 Deformation of membrane donor cells for erythrocyte hybrids. Control cells heated to $48^{\circ} \mathrm{C}$ for $10 \mathrm{~min}$, ISC, and untreated control cells were observed at 290 mos M. Graphs of $(L-W) /(L+W)$ vs. shear stress reveal moderately reduced deformability of heated cells and virtual absence of deformation by ISC compared with control cells. formed readily, and their diffraction patterns behaved in a manner very similar to those of intact normal cells. The diffraction of stationary ISC hybrids was also similar to that of intact ISC, with a horizontal ellipsoidal configuration. With application of shear stress, however, the ISC hybrids deformed and produced vertical patterns almost identical to those of the normal cell hybrids. The $(\mathrm{L}-\mathrm{W}) /(\mathrm{L}+\mathrm{W})$ curve was also close to that of normal cell hybrids (Fig. 8). The diffraction patterns obtained from heated cell hybrids were distinctly different from those of both ISC and normal cell hybrids. A vertically elongated pattern was produced upon application of shear stress, but its vertical edges were nearly parallel, and the smooth convergence of the ellipsoidal normal pattern was not apparent. Approximate measurements of the pattern length and width gave an $(\mathrm{L}-\mathrm{W}) /(\mathrm{L}+\mathrm{W})$ curve that ran above the curve for normal cell hybrids, because of the abnormal elongation of this pattern. The heated cell hybrids also behaved differently from the other hybrids when shear stress was removed abruptly by stopping the ektacytometer. Whereas both ISC and normal cell hybrids relaxed immediately, regenerating the pattern of stationary cells, the heated cell hybrids appeared to relax slowly. 2-3 min were required for the elongated diffraction pattern to return to its original circular form.

\section{DISCUSSION}

From these studies of the laser diffraction patterns of cells subjected to shear stress in the ektacytometer, we have developed an improved understanding of the

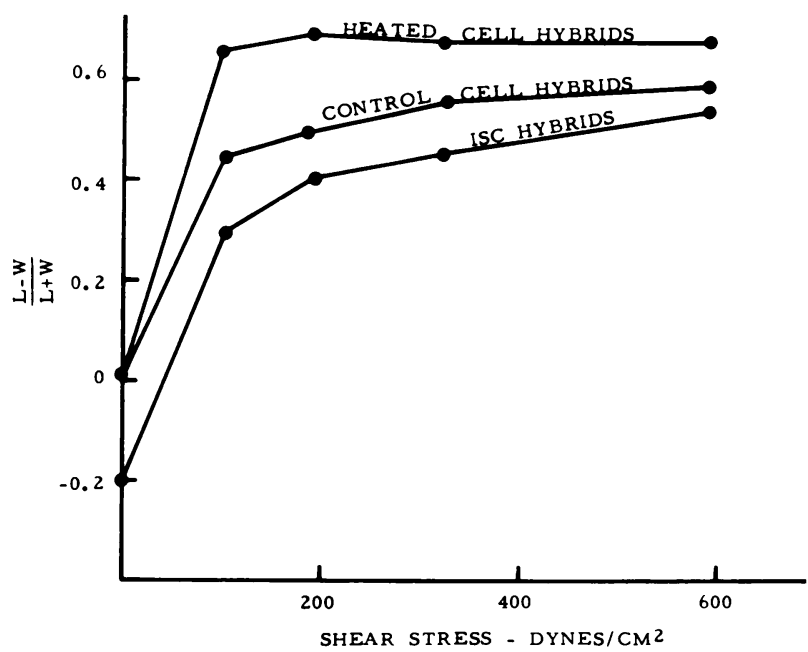

FIGURE 8 Deformation of erythrocyte hybrids, all with an MCHC of $19 \mathrm{~g} / \mathrm{dl}$. Measurement of diffraction patterns are plotted as $(\mathrm{L}-\mathrm{W}) /(\mathrm{L}+\mathrm{W})$ vs. shear stress. Note that deformation of ISC hybrids is close to that of normal hybrids, in contrast to the behavior of intact cells as shown in Fig. 7. Also, the curve for heated cell hybrids is above that for control hybrids, a reversal of the behavior for the intact cells. 
deformability behavior of sickle cells. Analysis of subpopulations of mature discoid cells and ISC isolated from Stractan gradients have confirmed the conclusions of Bessis and Mohandas (20) that sickle cells with normal morphology and normal MCHC deform like normal cells. ISC, on the other hand, produce a characteristic horizontal diffraction pattern, which changes little with increasing shear stress in isotonic medium. Bessis and Mohandas (20) have demonstrated that the pattern orientation of ISC results from perpendicular orientation of these poorly deformable cells to the direction of fluid flow. When the ISC were suspended in media of progressively decreasing osmolality, the characteristic ISC pattern was replaced under shear stress by the normal vertical ellipse characteristic of deforming cells orienting along the direction of shear stress. The restoration of deformability is best explained by a reduction in the internal viscosity of the cells as they take up water. This interpretation is supported by the similar behavior of artificially dehydrated normal cells, which were undeformable at MCHC of 44-46 g/dl, but which deformed readily when their MCHC was lowered to 34-36 g/dl. Cokelet and Meisselman (21) and Chien (2) have shown that the viscosity of both hemoglobin A and hemoglobin S solutions increase asymptotically as the concentration approaches $40 \mathrm{~g} / \mathrm{dl}$. Thus, the intracellular viscosity would increase several fold between 35 and $45 \mathrm{~g} / \mathrm{dl}$, the range of interest in these experiments.

The osmotic resistance of ISC in isotonic medium indicates that reduced surface-area:volume ratio is not a factor in their reduced deformability. However, because normal cells hemolyze at $125 \operatorname{mosM}$, it might have been expected that swelling of ISC at this low osmotic strength would have limited the cell deformation under these conditions; especially because ISC have been described as cells with reduced membrane surface, swelling could have countered to some extent the reduction of internal viscosity at low osmolality.

The ellipticity value for ISC at low osmolality tended to be lower than the isotonic value for deformable discoid cells, either sickle or normal controls, which suggests some possible limitation by reduced surface area. However, this could also have been the result of heterogeneity in the ICS populations. The fact that the least-dense subpopulation of ISC obtained from the hypotonic Stractan separation did deform at 150 mosM to the same extent as normal cells at 290 mosM supports the idea that heterogeneity in MCHC, rather than limitation of surface area, was responsible for the lower maximum deformation of total ISC populations obtained in single-stage Stractan separations. It should also be noted that studies previously reported from this laboratory (6) were unable to document any significant deficit of membrane lipids in ISC relative to mature discoid sickle cells. The hypothesis that surface area of ISC is not greatly reduced is further supported by the scanning electron micrographs of ISC at $125 \operatorname{mos}$ M. Most of the cells still showed biconcavities and therefore appeared to have adequate excess membrane to accomodate cell deformation.

Whereas a profound influence of osmolality and MCHC on deformability of ISC has now been demonstrated, the role of viscoelastic properties of the membrane is more difficult to define. Our experiments have used gently heated normal cells in an effort to isolate membrane effects from those of cell geometry and internal viscosity. Ektacytometer patterns of intact heated cells were characterized by reduced deformation at low values of applied shear stress. It is possible that the more gradual approach to maximum deformation by intact ISC in hypotonic medium also was a reflection of reduced membrane flexibility. However, the ISC diffraction pattern is complicated at low shear stress by reorientation effects, and interpretation is difficult at this stage.

The erythrocyte hybrid experiments were also expected to yield some insights into the role of membrane properties in ISC deformability. ISC hybrids behaved more like normal cells hybrids than like heated cell hybrids, from which it might be concluded that membrane viscoelastic properties of ISC were normal. However, some caution is still needed in interpreting these data, because the heated cell hybrids behaved in unusual manner. Rather than simulating the behavior of intact heated cells, with reduced pattern elongation at all shear stress values, the heated cell hybrids actually produced patterns with greater elongation, especially at low shear stress. Two alternative explanations of this unusual behavior might be considered. First, it is possible that the pattern elongation actually represents deformation of the heated cell hybrids. If so, they would appear to have deformed to a greater extent than the normal cell hybrids. In addition, the slow relaxation of the pattern when shear stress was removed suggests that viscoplastic flow of the membrane could have occurred. Such an effect of heating could be similar to the effects of Ca reported by Kuettner et al. (22), who observed that normal cells loaded with Ca relaxed more slowly than untreated controls after aspiration and release from a micropipet. The alternative explanation for the pattern elongation of heated cell hybrids is that the hybrids did not deform, but oriented in the shear stress field so that they presented an atypical edge-on profile to the laser beam. The linear, rather than curved, boundaries of the diffraction pattern we observed were reminiscent of diffraction patterns of undeformable llama cells, which were found to orient under low shear stress (23). The $(L-W) /(L+W)$ vs. shear stress curves also support this possibility in showing a rapid rise to 
a plateau value that is independent of the applied stress. If orientation were occurring, the slow relaxation on removal of stress would represent a gradual return to the original random orientation of the cells in suspension. At present, we are unable to distinguish between these alternative interpretations. Nevertheless, the observations themselves are consistent with the thesis that the viscoelastic properties of erythrocyte membranes were altered as a result of gentle heating, and that those alterations were reflected in abnormal behavior under shear stress.

Two other ektacytometer studies using a resealed membrane system were reported by Nakashima and Beutler $(24,25)$. In one study, they reported a reduction in the deformability of resealed erythrocyte membranes when anti-spectrin antibody was incorporated into the cell interior. In other experiments they found normal deformability of resealed hereditary spherocytosis membranes. From their observations they concluded that the ektacytometer measurements could reveal alterations in the viscoelastic properties of erythrocyte membranes and that membranes of hereditary spherocytes were normal in this regard. However, because the changes in diffraction patterns attributed to membrane alterations are so subtle, caution in interpreting these data should be used until more extensive studies have been performed. With this caveat, our results with resealed ISC membranes suggest that reduced membrane flexibility is not the major factor limiting the deformability of intact ISC.

The restoration of ISC deformability at low MCHC and in the erythrocyte hybrid system suggests that high $\mathrm{MCHC}$ is a major determinant of reduced deformability in the oxygenated ISC. Hitherto, it has been frequently stated that membrane rigidity, perhaps secondary to $\mathrm{Ca}$ accumulation, was primarily responsible for the failure of ISC to deform. Chien et al. $(1,2)$ noted the influence of MCHC, but also concluded that membrane rigidity lowered the deformability of both ISC and non-ISC. La Celle (8) and, more recently, Havell et al. (26) also reported reduced membrane flexibility in ISC. However, it should be pointed out that the use of a relatively large micropipet in those experiments did not clearly isolate membrane effects from those of internal viscosity, and it is likely that the high $\mathrm{MCHC}$ also contributed to the reduced deformability of ISC in those studies.

These experiments provide the first direct demonstration of the influence of MCHC upon ISC deformability. Cell water loss is the direct result of altered cation permeability, which is in some way induced by the sickling process. This dehydration, in turn, exerts a profound effect upon intracellular viscosity, which finally may reduce cell survival. Even when fully oxygenated, ISC are so undeformable that they are prob- ably vulnerable to removal from the circulation by the reticuloendothelial system. A similar mechanism presumably underlies the shortened erythrocyte lifetime in patients with "desiccytosis," a disorder characterized by dehydrated cells with high MCHC (14). In addition, the reduced deformability of oxygenated ISC might endow them with the capacity to initiate blockades in the microcirculation even where oxygen saturation is adequate for circulating deformable cells of normal MCHC. This, with their propensity for extremely rapid hemoglobin polymerization upon deoxygenation (27), supports the concept of a major influence of high MCHC in the pathophysiology of ISC.

The relative importance of MCHC, surface-area: volume ratio, and altered membrane properties in the survival of pathologic erythrocytes needs to be explored further. In particular, the role of reduced membrane flexibility is not yet clearly defined. These studies clearly demonstrate the need to consider MCHC, along with possible changes in membrane viscoelasticity, in the reduced deformability and shortened lifetime of ISC.

\section{ACKNOWLEDGMENTS}

This work was supported in part by U. S. Public Health Service grants HL-20985-01, AM16095, and HL-07100-03.

\section{REFERENCES}

1. Chien, S., S. Usami, and J. F. Bertles. 1970. Abnormal rheology of oxygenated blood in sickle cell anemia. $J$. Clin. Invest. 49: 623-634.

2. Chien, S. 1977. Rheology of sickle cells and erythrocyte content. Blood Cells. 3: 279-294.

3. Murphy, J. R., M. Wengard, and W. Brereton. 1976. Rheological studies of HbSS blood: influence of hematocrit hypertonicity, separation of cells, deoxygenation, and mixture with normal cells. J. Lab. Clin. Med. 87: 475-486.

4. Padilla, F., P. A. Bromberg, and W. N. Jensen. 1973. The sickle-unsickle cycle: a cause of cell fragmentation leading to permanently deformed cells. Blood. 41: 635660.

5. Glader, B. E., and D. G. Nathan. 1978. Cation permeability alterations during sickling and generation of irreversibly sickled cells. Blood. 51: 983-989.

6. Clark, M. R., R. C. Unger, and S. B. Shohet. 1978. Monovalent cation composition and ATP and lipid content of irreversibly sickled cells. Blood. 51: 1169-1178.

7. Glader, B. E., S. E. Lux, A. Muller-Soyano, O. S. Platt, R. D. Propper, and D. G. Nathan. 1978. Energy reserve and cation composition of irreversibly sickled cells in vivo. Br. J. Haematol. 40: 527-532.

8. La Celle, P. L. 1975. Pathologic erythrocytes in the capillary microcirculation. Blood Cells. 1: 269-284.

9. Palek, J. 1977. Red cell membrane injury in sickle cell anaemia. Br. J. Haematol. 35: 1-9.

10. Eaton, J. W., H. S. Jacob, and J. G. White. 1979. Membrane abnormalities of irreversibly sickled cells. Semin. Hematol. 16: 52-64.

11. Eaton, J. W., T. D. Skelton, H. S. Swofford, C. E. Kolpin, and H. S. Jacob. 1973. Elevated erythrocyte calcium in sickle cell disease. Nature (Lond.). 246: 105-106. 
12. Palek, J. 1977. Red cell calcium content and transmembrane calcium movements in sickle cell anemia. J. Lab. Clin. Med. 89: 1365-1374.

13. Glader, B. E., N. Fortier, M. M. Albala, and D. G. Nathan. 1974. Congenital hemolytic anemia associated with dehydrated erythrocytes and increased potassium loss. N. Engl. J. Med. 291: 491-496.

14. Clark, M. R., N. Mohandas, V. Caggiano, and S. B. Shohet. 1978. Effects of abnormal cation transport on deformability of disiccytes. J. Supramol. Struct. 8: 521-532.

15. Bessis, M., and N. Mohandas. 1975. A diffractometric method for the measurement of cellular deformability. Blood Cells. 1: 307-313.

16. Clark, M. R., N. Mohandas, and S. B. Shohet. 1978. Deformability of irreversibly sickled cells: influence of MCHC. Blood. 52(Suppl. 1): 96. (Abstr.)

17. Bessis, M., and R. I. Weed. 1973. The structure of normal and pathologic erythrocytes. Adv. Biol. Med. Phys. 14: 35-91.

18. Rakow, A. L., and R. M. Hochmuth. 1975. Effect of heat treatment on the elasticity of human erythrocyte membrane. Biophys. J. 15: 1095-1100.

19. Clark, M. R., and S. B. Shohet. 1976. Hybrid erythrocytes for membrane studies in sickle cell disease. Blood. 47: $121-131$.
20. Bessis, M., and N. Mohandas. 1977. Laser diffraction patterns of sickle cells in fluid shear fields. Blood Cells. 3: 229-239.

21. Cokelet, G. R., and H. J. Meisselman. 1962. Rheological comparison of hemoglobin solutions and erythrocyte suspensions. Science (Wash. D. C.). 162: 275-277.

22. Kuettner, J. F., K. L. Dreher, G. H. R. Rao, J. W. Eaton, P. L. Blackshear, and J. G. White. 1977. Influence of the ionophore A23187 on the plastic behavior of normal erythrocytes. Am. J. Pathol. 88: 81-94.

23. Smith, J. E., N. Mohandas, and S. B. Shohet. 1979. Variability of erythrocyte deformability among various mammals. J. Appl. Physiol. 236: H725-H730.

24. Nakashima, K., and E. Beutler. 1978. Effect of antispectrin antibody and ATP on deformability of resealed erythrocytes.Proc. Natl. Acad. Sci.U. S. A. 75: 3823-3825.

25. Nakashima, K., and E. Beutler. 1979. Erythrocyte cellular and membrane deformability in hereditary spherocytosis. Blood. 53: 481-485.

26. Havell, T. C., D. Hillman, and L. S. Lessin. 1978. Deformability characteristics of sickle cells by microelastimetry. Am. J. Hematol. 4: 9-16.

27. Hahn, J. A., M. J. Messer, and T. B. Bradley. 1976. Ultrastructure of sickling and unsickling in time-lapse studies. Br. J. Haematol. 34: 559-565. 